Т. КИИПЛИ, Я. КИВИСИЛЛА,

\title{
ЭВОЛЮЦИЯ ХИМИЧЕСКОГО СОСТАВА ИЗВЕСТНЯКОВ ОРДОВИКА И СИЛУРА ЭСТОНИИ
}

В ходе геохимического исследования карбонатных пород Эстонии в 1973-1982 гг. отобрано и проанализировано с помощью приближенноколичественного спектрального анализа около 6000 проб известняков, что позволило выяснить основные закономерности поведения изученных элементов в разрезе. Некоторые аспекты распределения микроэлементов в карбонатных породах Әстонии рассматриваются в ранее опубликованных работах (Вингисаар и др., 1979, 1981). Анализы выполнены аналитиками К. Орловой и В. Варес в лаборатории Управления геологии ЭССР.

За период работы усовершенствовались методика и применяемая аппаратура спектрального анализа, вследствие чего к концу работы значительно расширился круг определяемых элементов и повысилась достоверность результатов. Выводы по Тi, $\mathrm{V}, \mathrm{Cr}, \mathrm{Mn}, \mathrm{Co}, \mathrm{Ni}, \mathrm{Cu}, \mathrm{Pb}$, $\mathrm{Ga}, \mathrm{Sr}, \mathrm{Ba}, \mathrm{Al}, \mathrm{Fe}, \mathrm{Mg}$ опираются на полный набор проб (табл. 1), в то время как закономерности распределения $\mathrm{Zr}, \mathrm{F}, \mathrm{Y}, \mathrm{Yb}, \mathrm{La}, \mathrm{Ce}$, $\mathrm{Be}, \mathrm{P}, \mathrm{Sc}, \mathrm{Si}, \mathrm{Ca}, \mathrm{Na}, \mathrm{K}$ выявлены в основном по материалам глубинного геологического картирования площади Таллин-Кырвемаа.

Постоянный контроль и выравнивание результатов анализа с помощью созданной коллекции контрольных образцов осуществлялись на ЭВМ (Кивисилла, 1975). В результате принятых мер достоверность (табл. 2) окончательных данных значительно превышает требования, предъявляемые полуколичественному спектральному анализу, и по воспроизводимости многих элементов $(\mathrm{Cr}, \mathrm{Mn}, \mathrm{Ni}, \mathrm{Cu}, \mathrm{Pb}, \mathrm{Sr}, \mathrm{Ba})$ не уступает количественным методам III или IV категории (OCT 41-08212-82).

Поскольку целью настоящего исследования является выяснение седиментационных (или седиментационно-диагенетических) закономерностей, вторично доломитизированные породы здесь не рассмотрены. При исследовании площади Таллин-Кырвемаа доломиты, распространенные лишь в незначительной мере (прослоями в породах нижнего ордовика и ласнамягиского горизонта), не исключались из рассмотрения. В связи с этим в корреляционной матрице появляется и доломитовая ассоциация элементов. Анализ геохимических данных в настоящей работе проведен отдельно по северной и южной структурнофациальным зонам, выделяемым для ордовика и силура Прибалтики (Мянниль, 1966; Кальо, 1977).

\section{Корреляционные матрицы}

Для выделения естественных ассоциаций элементов в карбонатных породах вычислены коэффициенты парной корреляции. Основой для корреляционного анализа послужили усредненные данные мелких стратиграфических подразделений (горизонты, пачки). Исследование матриц 

$\mathrm{Ga}, \mathrm{Cr}, \mathrm{Cu}, \mathrm{Fe}, \mathrm{Zr}, \mathrm{V}, \mathrm{Sc}, \mathrm{La}, \mathrm{Na}$, $\mathrm{Co}, \mathrm{Ni}, \mathrm{Be}, \mathrm{Yb}$ имеют между собой сильные корреляционные связи (с уровнем значимости $5 \%$ ). Поскольку кларки этих элементов в глинистых породах в среднем на порядок выше, чем в карбонатных, очевидно, эти корреляционные связи обусловлены изменениями содержания алевролитовопелитового терригенного материала в известняках. В ту же терригенную ассоциацию частично вхо. дит и Се, в известняках иногда Y и Mg. В мергелях к терригенной ассоциации присоединяется свинец, а в известняках северной

\section{Распределение фактического материала}

\begin{tabular}{|c|c|c|c|}
\hline \multirow{3}{*}{$\begin{array}{l}\text { Страти- } \\
\text { графиче- } \\
\text { ская } \\
\text { единица }\end{array}$} & \multicolumn{3}{|c|}{ Количество проб } \\
\hline & & $\begin{array}{r}\text { Северная } \\
\text { ная }\end{array}$ & $\begin{array}{l}\text { фациаль- } \\
\text { зона }\end{array}$ \\
\hline & $\begin{array}{l}\text { Южная } \\
\text { фациаль- } \\
\text { ная зона }\end{array}$ & итого: & $\begin{array}{c}\text { в том } \\
\text { числе } \\
\text { площадь } \\
\text { Таллин- } \\
\text { Кырве- } \\
\text { маа }\end{array}$ \\
\hline $\begin{array}{l}\mathrm{S}_{2} \\
\mathrm{~S}_{1} \\
\mathrm{O}_{3} \\
\mathrm{O}_{2} \\
\mathrm{O}_{1}\end{array}$ & $\begin{array}{r}26 \\
783 \\
147 \\
312 \\
59\end{array}$ & $\begin{array}{r}48 \\
807 \\
1350 \\
2836 \\
253\end{array}$ & $\begin{array}{r}- \\
\overline{91} \\
510 \\
67\end{array}$ \\
\hline Итого: & 1327 & 5294 & 668 \\
\hline
\end{tabular}
фациальной зоны -- марганец.

Кальций же находится в отрицательной корреляции с большинством элементов терригенной ассоциации. В силурийских породах Южной Эстонии также явно отрицательно связан с элементами терригенной ассоциации стронций, что обусловлено его аномально высоким содержанием в породах райккюлаского горизонта. Инертно ведут себя в большинстве случаев $\mathrm{Sr}, \mathrm{Mg}, \mathrm{Pb}, \mathrm{Mn}$, иногда $\mathrm{Ni}$.

По материалам площади Таллин-Қырвемаа возможна следующая дешифровка ассоциаций (рис. 1).

1. Терригенная в широком смысле: $\mathrm{Sc}, \mathrm{Cu}, \mathrm{Co}, \mathrm{Yb}, \mathrm{Na}, \mathrm{K}, \mathrm{Ga}, \mathrm{V}, \mathrm{Ti}$, $\mathrm{Cr}, \mathrm{La}, \mathrm{Ba}, \mathrm{Ni}, \mathrm{Al}, \mathrm{Si}, \mathrm{Be}, \mathrm{Zr}, \mathrm{Fe}, \mathrm{Ce},(\mathrm{F}, \mathrm{Y}, \mathrm{Mn}, \mathrm{P})$;

а) существенно глинистая: $\mathrm{K}, \mathrm{Ga}, \mathrm{V}, \mathrm{Ti}, \mathrm{Cr}, \mathrm{La}, \mathrm{Ba}, \mathrm{Al}, \mathrm{Si}, \mathrm{Zr}$ (не поддается корреляции с фосфатной ассоциацией);

б) акцессорная: $\mathrm{Yb}, \mathrm{Fe}, \mathrm{Sc}, \mathrm{Cu}, \mathrm{Co}, \mathrm{Na}, \mathrm{Ni}, \mathrm{Be}(\mathrm{Y}, \mathrm{P}, \mathrm{F}, \mathrm{Mn})$, в том числе существенно фосфатная - Y, P, F;

2. Доломитовая $\mathrm{F}, \mathrm{Yb}, \mathrm{Fe}, \mathrm{Mn}, \mathrm{Mg}$;

3. Известковая $\mathrm{Ca}(\mathrm{Sr}, \mathrm{Pb})$.

Коэффициенты корреляции Al (как показателя глинистой составляющей $)$ с $M n(-0,2 \ldots-0,22)$, Y $(0,15 \ldots 0,25)$, F $(-0,02 \ldots 0,07)$, P $(-0,02 \ldots 0,01)$ существенно не отличаются от нуля, т. е. изменение содержания этих элементов не обусловлено изменением содержания глинистой составляющей.

Обращает на себя внимание хорошая корреляция Ва и $\mathrm{Fe}$ - элементов, поступающих в бассейн осадконакопления частично в составе терригенных минералов, а частично в виде коллоидных и истинных растворов - преимущественно с терригенными элементами. В прибрежной зоне в результате коагуляции и реакции с сульфат-ионом эти элементы осаждаются и далее распределяются аналогично тонкому терригенному материалу под контролем гидродинамических процессов (Яночкина, 1966), что обусловливает корреляцию с другими элементами терригенной ассоциации.

Причиной четкой корреляции халькофильных элементов с существенно терригенной ассоциацией, по-видимому, является их сорбция из морской воды на глинистых частицах и дальнейший диагенетический переход в сульфидную форму или в структуру глинистых минералов, Вероятно, аналогично образуется и примесь доломита в известняках, что обусловливает связь элементов доломитовой ассоциации с элемен- 


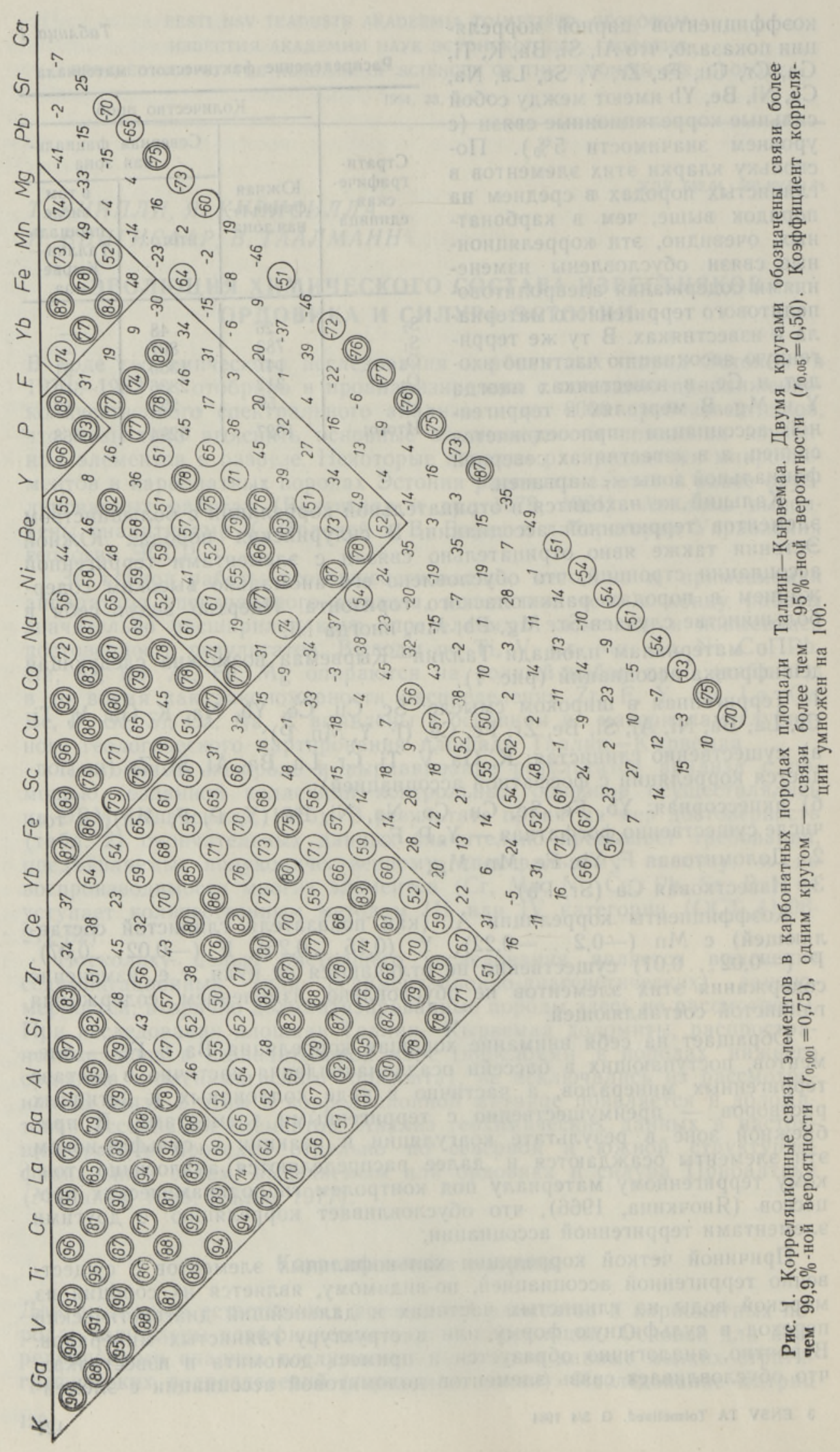


тами терригенной. По мнению Ю. К. Буркова (1972), совмещенность элементов, характерных базитовым ( $\mathrm{Ti}, \mathrm{V}, \mathrm{Cr}, \mathrm{Co}, \mathrm{Ni}, \mathrm{Cu}$ ) и гранитоидным породам $(\mathrm{Zr}, \mathrm{Y}, \mathrm{Be}, \mathrm{Ba})$, наблюдаемая в наших породах, говорит о глубоком химическом выветривании исходных пород в условиях сглаженного рельефа областей сноса.

\section{Цикличность в содержании элементов терригенной ассоциации}

Как показал анализ корреляционных матриц, основным фактором, контролирующим распределение преобладающего большинства химических элементов в карбонатной породе, является содержание терригенного компонента. Эта главная закономерность проявляется в вертикальном разрезе как цикличность содержания этих элементов (рис. 2). Цикличность некоторых элементов (Ba, Fe) четко проявляется в южной фациальной зоне (в центре бассейна седиментации), в северной фациальной зоне она в целом выражена слабее. Причиной этого может быть более тонкодисперсная форма миграции этих элементов, чем Si, $\mathrm{Al}, \mathrm{Cr}$ и др. Максимумы содержания терригенных элементов в южной фациальной зоне приурочены к оандускому, вормсискому, адаверескому-яагарахускому и охесаарескому горизонтам. В северной фациальной зоне отчетливый максимум наблюдается только в адаверескомяаниском горизонтах. Остальные пики слабые и распадаются на более мелкие максимумы, чем в южной зоне. Общеизвестно, что отложения центральной части бассейна в ордовике и силуре Прибалтики более глинистые, а ближе к берегу становятся более карбонатными. Поэтому причиной терригенной цикличности можем считать трансгрессии и регрессии моря и связанные с ними передвижения фаций.

\section{Вертикальные направленные изменения в составе карбонатных пород}

Фосфатная ассоциация (P, F, Y) максимально концентрируется в кундаском горизонте. Вверх по разрезу эти элементы быстро убывают, фосфор улавливается выше предела чувствительности анализа еще в ухакуском горизонте, фтор и иттрий прослеживаются до верхнего ордовика. По мнению авторов, эти элементы поступали в карбонатные породы из фосфоритов нижнего ордовика при размыве в кундаское время. О том же сильном размыве более древних отложений свидетельствует значительный перерыв в осадконакоплении, выраженный в Северной Эстонии отсутствием нижнего подгоризонта кундаского горизонта. Относительно низкое содержание этих элементов в породах волховского горизонта говорит о более слабом размыве, возможно, что эрозионный срез достигал только глауконитовых песчаников латорпского горизонта.

Содержание марганца отчетливо уменьшается вверх по разрезу. Максимальные содержания в северной фациальной зоне встречаются в базальной части карбонатного разреза от пяйтеской пачки латорпского до ласнамягиского горизонта включительно. В южной фациальной зоне высокие содержания наблюдаются во всем разрезе ордовика, на границе с силуром происходит резкое понижение количества марганца в породах. При этом в ордовике наблюдаются два цикла с максимальными значениями в интервалах от ласнамягиского до идавереского и от набалаского до поркуниского горизонтов. Уменьшение содержания марганца в течение ордовика и силура можно обьяснить, по теории А. В. Ронова и А. И. Ермишкиной (1959), аридизацией климата. 

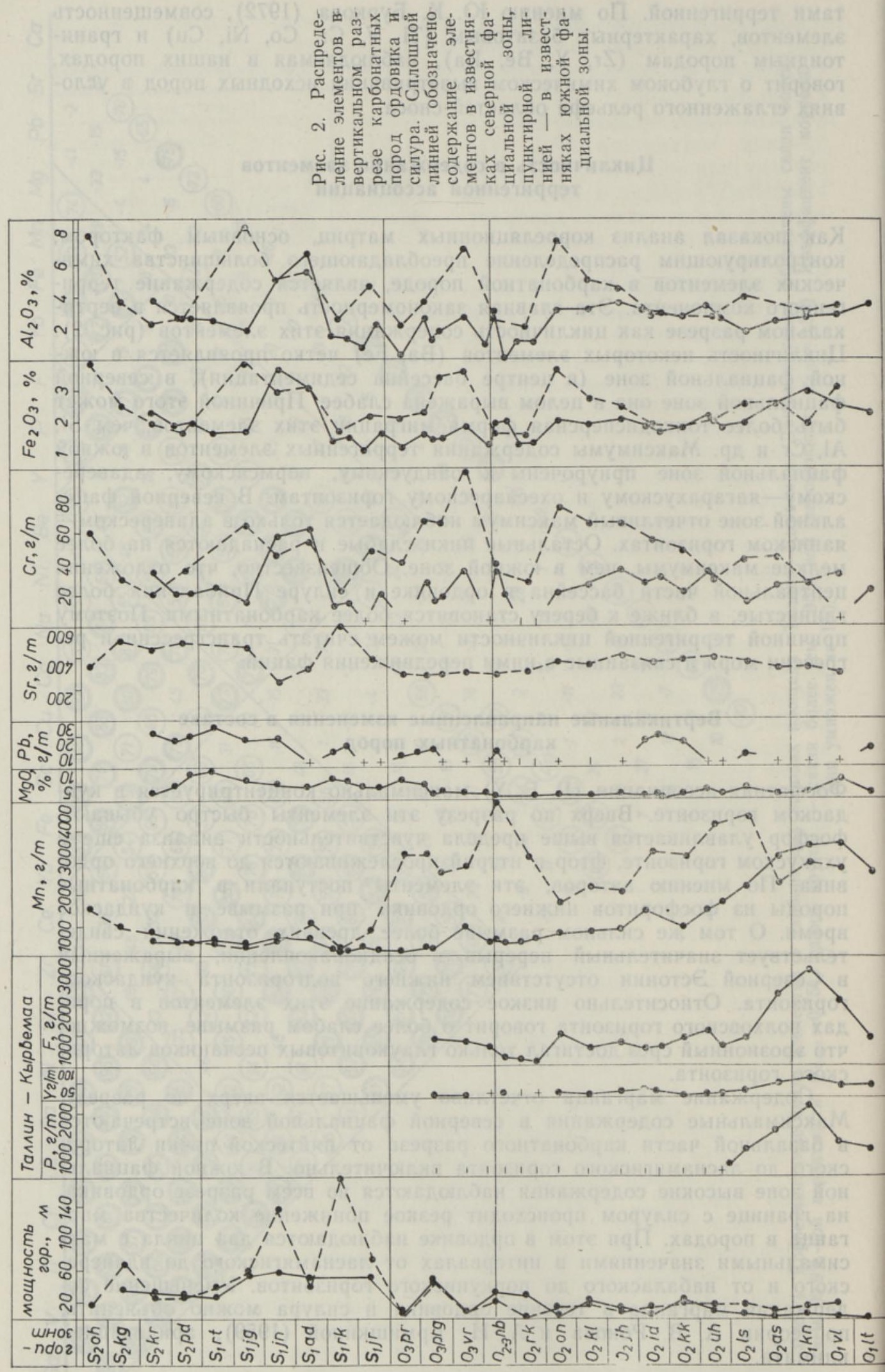
Достоверность результатов спектрального анализа карбонатных пород (коэффициент вариации, \%)

\begin{tabular}{|c|c|c|c|c|c|c|}
\hline \multirow{3}{*}{$\begin{array}{c}\text { Эле- } \\
\text { менты }\end{array}$} & $\begin{array}{c}1973- \\
1981\end{array}$ & \multicolumn{5}{|c|}{$\begin{array}{c}\text { 1981-1982 (глубинное геологическое } \\
\text { картирование площади Таллин-Кырвемаa }\end{array}$} \\
\hline & \multirow{2}{*}{$V_{1}$} & \multirow{2}{*}{$V_{2}$} & \multicolumn{2}{|c|}{$V_{3}$} & \multicolumn{2}{|c|}{$V_{4}$} \\
\hline & & & K & $\Pi$ & K & $\Pi$ \\
\hline $\mathrm{Ti}$ & 42 & 33 & 26 & 18 & 19 & 16 \\
\hline $\mathrm{V}$ & 49 & 38 & 53 & 42 & 19 & 19 \\
\hline $\begin{array}{l}\mathrm{Cr} \\
\mathrm{Mn}\end{array}$ & 30 & 33 & 18 & 26 & 23 & 17 \\
\hline $\begin{array}{l}\mathrm{Mn} \\
\mathrm{Co}\end{array}$ & 41 & 24 & 18 & 20 & 20 & 18 \\
\hline $\begin{array}{l}\mathrm{Co} \\
\mathrm{Ni}\end{array}$ & 37 & 31 & 35 & 43 & 19 & 22 \\
\hline $\begin{array}{l}\mathrm{Ni} \\
\mathrm{Cu}\end{array}$ & 30 & 28 & 31 & 29 & 20 & 15 \\
\hline $\begin{array}{l}\mathrm{Cu} \\
\mathrm{Pb}\end{array}$ & 23 & 32 & 21 & 28 & 22 & 20 \\
\hline $\mathrm{Pb}$ & 23 & 37 & 26 & 27 & 22 & 21 \\
\hline $\begin{array}{l}\mathrm{Ga} \\
\mathrm{Zr}\end{array}$ & 18 & 37 & 21 & 37 & 16 & 12 \\
\hline $\begin{array}{l}\mathrm{Zr} \\
\mathrm{Y}\end{array}$ & - & - & 36 & -0 & 20 & - \\
\hline $\mathrm{Y}$ & - & - & 39 & - & 26 & - \\
\hline $\mathrm{Yb}$ & - & 15 & 23 & - & 19 & - \\
\hline $\begin{array}{l}\mathrm{La} \\
\mathrm{Be}\end{array}$ & - & - & $\begin{array}{l}68 \\
16\end{array}$ & $\bar{E}$ & $\overline{19}$ & $\overline{-}$ \\
\hline $\mathrm{Sr}$ & 36 & 27 & 24 & 24 & 22 & 7 \\
\hline $\mathrm{Ba}$ & 38 & 30 & 21 & 23 & 23 & 13 \\
\hline $\begin{array}{l}\mathrm{P} \\
\mathrm{Sc}\end{array}$ & - & 30 & & 57 & 7 & 12 \\
\hline $\begin{array}{l}\mathrm{Sc} \\
\mathrm{Si}\end{array}$ & $\overline{-}$ & - & 38 & $\overline{-}$ & 22 & - \\
\hline $\begin{array}{l}\mathrm{Si} \\
\mathrm{Al}\end{array}$ & $\overline{50}$ & - & $\overline{24}$ & $\overline{-}$ & $\begin{array}{l}19 \\
15\end{array}$ & - \\
\hline $\mathrm{Fe}$ & 28 & - & 22 & - & 18 & - \\
\hline $\mathrm{Mg}$ & 21 & & 20 & - & 17 & - \\
\hline $\mathrm{Ca}$ & 170 & - & 16 & - & 10 & $\overline{1}$ \\
\hline $\begin{array}{l}\mathrm{Na} \\
\mathrm{K}\end{array}$ & & - & $\overline{-}$ & $\begin{array}{l}11 \\
20\end{array}$ & $\bar{z}$ & $\begin{array}{l}13 \\
15\end{array}$ \\
\hline & & & & & & \\
\hline
\end{tabular}

Примеч ание. $\mathrm{V}-$ коэффициент вариации (\%) результатов спектрального анализа; $\mathrm{V}_{1}, \mathrm{~V}_{2}-$ воспроизводимость результатов анализов разных партий $\left(\mathrm{V}_{1}-\right.$ сопоставление усредненных данных разных партий проб по методам «канала» - K, и «просыпки» - П, $\mathrm{V}_{2}$ - coпоставление данных, полученных методами $\mathrm{K}$ и П); $\mathrm{V}_{3}-$ воспронзводимость привязки результатов к принятому уровню наиболее вероятных содержаний (по данным анализа коллекции контрольных образцов); $\mathrm{V}_{4}-$ воспроизводимость результатов анализов одной партин.

Об аридном климате в силуре свидетельствуют также венлокские гипсоносные породы, найденные в Литве (Коркутис и др., 1972). Подтверждением гумидного климата в начале ордовика являются также железистые оолиты в нижнем ордовике Эстонии и примесь каолинита в нижнеордовикских породах Латвии (Пылма, 1982).

В настоящее время нельзя еще с полной уверенностью объяснить поведение марганца в разрезе карбонатных пород Эстонии, ибо мы имеем дело с наложением результатов нескольких процессов, выражающихся в уменьшении его содержания вверх по разрезу, в доминирующей концентрации в более глубокой части бассейна и в некоторой неясной корреляции с терригенной частью пород. О климатическом контроле было сказано выше.

Содержание магния и свинца в северной фациальной зоне увеличивается от верхнего ордовика до конца силура (рис. 2). Повышение содержания магния в известняках свидетельствует о повышении температуры в среде осадконакопления, причиной которого могут быть потепление климата и (или) обмеление моря. Увеличение содержания свинца также можно объяснить потеплением моря, поскольку в теплых 
морях в бо́льшем количестве осаждается арагонит, структура которого способна изоморфно включить крупные катионы (Pb, $\mathrm{Sr}$ ). По материалам площади Таллин-Кырвемаа свинец хорошо коррелируется с фосфором. Содержание свинца в более глинистых породах южной фациальной зоны подчиняется терригенной цикличности.

В южной фациальной зоне содержание стронция в силурийских породах выше, чем в ордовикских. В райккюласком горизонте постепенно увеличивается содержание $\mathrm{Sr}$ снизу вверх. Породы иклаской пачки содержат в среднем $0,1 \%$ стронция, что в 4 раза превышает средние данные по всем карбонатным породам Эстонии. Максимальное количество в единичных пробах достигает $0,25 \%$. В современных кальцитовых осадках содержится также около $0,1 \% \mathrm{Sr}$, в арагонитовых около $1 \%$. Первичные арагонит и магнезнальный кальцит перекристаллизовываются при диагенезе осадка в нормальные кальцит и доломит, а стронций вынашивается (Kinsman, 1969). Высокое содержание стронция в древних породах свидетельствует, что эти породы проходили диагенетическое преобразование в замкнутой или полузамкнутой системе, которая способствовала сохранению стронция (Юдович и др., 1980). Сохранению стронция способствует и быстрая седиментация и захоронение осадка.

Кажется вероятным, что более интенсивное карбонатонакопление в силуре и наблюдаемые особенности распределения марганца, стронция и магния обусловлены как потеплением, так и аридизащией климата. Главным фактором, контролирующим распределение преобладающего большинства микроэлементов в карбонатных породах, является величина содержания терригенного материала. На фоне этого в вертикальном разрезе выявляются некоторые направленные изменения в составе известняков, которые можно объяснить переотложением более древних осадков (P, Y, F), аридизацией и потеплением климата $(\mathrm{Mn}, \mathrm{Mg})$ и изменением скоростей накопления осадков (Sr).

\section{ЛИТ Е Р А У РА}

Бурков Ю. К. Ассоцнации химических элементов и ряды их подвижности. - В кн.: Опорный разрез силура и нижнего девона Подолии. Л., 1972, 199-210.

Вингисаар П., Гулова Х., Кийпли T., Таалманн В. Распределение микроэлементов в карбонатных породах ордовика и силура Эстонии. - Изв. АН ЭССР. Геол., $1981,30,106-110$.

Вингисаар П., Гулова Х., Кийлли T., Таалманн В. Вещественный состав палеозойских карбонатных пород Эстонии. - Изв. АН ЭССР. Геол., 1979, 28, 45-51.

Кальо Д. Л. Структурно-фащнальное районированне снлура Прибалтики. - В кн.: Фации и фауна силура Прибалтикн. Таллин, 1977, 6-13.

Кивисилла Я. Снстема программ «Базальт» для математической обработки массовой геохимической информации на ЭВМ. - В кн.: Опыт и методика геохимических исследований и понсков месторождений полезных ископаемых в кристаллическом фундаменте Белоруссии и Прибалтики. Минск, 1975, 65-69.

Коркутис В. А., Лапинскас П. П., Лашков Е. М. Литология и фации нефтеносных отложений нижнего палеозоя Южной Прибалтики. М., 1972.

Мянниль P. М. История развития Балтийского бассейна в ордовике. Таллин, 1966. ОСТ 41-08-212-82. Управление качеством аналитической работы. Классификация методов анализа минерального сырья по точности результатов.

Пылма Л. Сравнительная литология карбонатных пород ордовика Северной и Средней Прибалтики. Таллин, 1982.

Ронов А. Б., Ермицкина А. И. Распределение марганца в осадочных породах. Геохим., 1959, 3, 206-225.

Юдович Я. Э., Майдл Г. В., Нванова Т. И. Геохимня стронция в карбонатных отложениях. Л., 1980.

Яночкина З. А. Статистические методы изучения пестроцветов. М., 1966.

Kinsman, $D . J . J$. Interpretation of $\mathrm{Sr}^{2+}$ concentrations in carbonate minerals and rocks. - J. Sedim. Petrol., 1969, 39, 486-508. 


\section{EESTI ORDOVIITSIUMI JA SILURI LUBJAKIVIDE KEEMILISE KOOSTISE EVOLUTSIOON}

Ordoviitsiumi ja siluri lubjakivides on spektraalanalüüsiga määratud 27 keemilise elemendi sisaldus. Enamiku elementide esinemine karbonaatkivimis sõltub terrigeense materjali sisaldusest, mis muutub vertikaalläbilõikes tsükliliselt. Selle pōhiseaduspärasuse foonil ilmnevad vertikaalläbilõikes suunatud muutused elementide sisalduses. See on seletatav vanemate kivimite ümbersettimisega $(\mathrm{F}, \mathrm{P}, \mathrm{Y})$, kliima soojenemise ja ariidseks muutumisega siluris ( $\mathrm{Mn}, \mathrm{Mg}$ ) ning sedimentatsiooni kiiruse muutumisega (Sr).

\section{T. KIIPLI, J. KIVISILLA, \\ P. VINGISAAR, V. TAALMANN}

\section{EVOLUTION OF THE CHEMICAL COMPOSITION OF ESTONIAN ORDOVICIAN AND SILURIAN LIMESTONES}

In Estonian Ordovician and Silurian limestones, the presence of 27 chemical elements has been defined by spectral analysis. The distribution of the majority of those elements depends on the content of terrigenous material in carbonate rocks whose changes are of a cyclic character in the vertical section. On the background of the main regularity there appear changes in the content of some elements in the vertical direction. This can be explained by the redeposition of the older rocks $(F, P, Y)$, by the climate getting warmer and more arid in the Silurian $(M n, M g)$, and by the changes in the velocity of sedimentation $(\mathrm{Sr})$. 